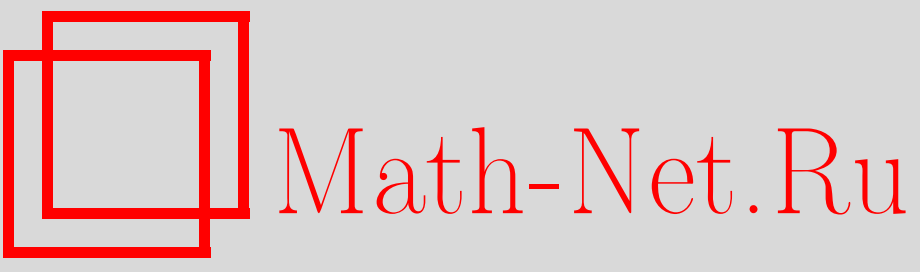

А. Г. Витушкин, Полвека - как один день, УМН, 2002, том 57, выпуск 1, 191-206

DOI: https://doi.org/10.4213/rm494

Использование Общероссийского математического портала Math-Net.Ru подразумевает, что вы прочитали и согласны с пользовательским соглашением

http://www.mathnet.ru/rus/agreement

Параметры загрузки:

IP : 3.85 .7 .115

26 апреля 2023 г., $17: 46: 00$ 


\title{
ПОЛВЕКА - КАК ОДИН ДЕНЬ
}

\author{
А. Г. Витушкин
}

Открылась бездна звезд полна; Звездам числа нет, бездне - дна.

М.В. Ломоносов

В статье рассказьвается о результатах работы одного из семинаров механико-математического факултета Московского университета и о нескольких встречах автора с замечательными математиками.

1. Как учиться математике? В университете на первом курсе я попал в хороший, необычный для того времени, семинар - кружок по теории функций для первокурсников (1949 г.). Руководил семинаром молодой доктор наук Александр Семенович Кронрод. На первом занятии он сказал, что его можно называть просто Саша. Особое расположение к Саше Кронроду определилось как-то сразу.

Его студенческие годы пришлись на время войны. В 1941 году он, закончив третий курс, добровольцем ушел на фронт. Имеет фронтовые награды орден Красной Звезды, орден Красного Знамени, орден Отечественной Войны и др. После тяжелого ранения, пролежав больше года в госпиталях, был демобилизован (1944г.). Вернувшись в университет, закончил два последних курса и аспирантуру, одновременно работая в курчатовском институте. За диссертационную работу, минуя степень кандидата, ему присвоили степень доктора наук. Его руководителем был Николай Николаевич Лузин.

По сложившейся в то время традиции семинары для студентов младших курсов были реферативными - студенты делали доклады по тем или иным темам, дополняющим лекционные курсы. Стиль кронродовского семинара был иным. Это был тренировочный семинар. В течение первого года занятий никаких докладов не было, весь материал прорабатьвался в виде упражнений. Кружок собирался раз в неделю, но на подготовку уходило по

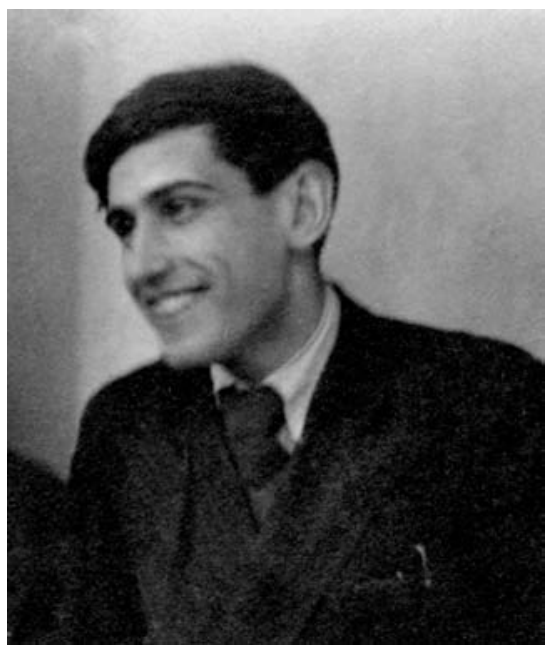

А. С. Кронрод - основатель научной школы

несколько часов ежедневно. Поэтому вскоре число участников значительно сократилось. А для тех, кто принял предложенньй темп, работа в семинаре оказалась весьма полезной. За один год кружок перерос в полноценньй научньй семинар.

Первьй научный результат в семинаре появился в конце первого года занятий. Автором был Роберт Минлос. Эта работа была представлена А. Н. Колмогоровым для опубликования в ДАН. Публикация статьи первокурсника в центральном академическом журнале факт неординарный, и случается это, как известно, не каждый год. Моя первая работа была выполнена на втором курсе и годом позже была доложена на заседании Московского математического общества. Таким образом, работа семинара признавалась успешной. Но никакой должности на факультете Кронрод не имел (все это время он работал в институте физических проблем), и при подаче на- 
ших курсовых ему каждый раз приходилось просить кого-нибудь фиктивно взять на себя руководство этими работами. Это не способствовало пополнению семинара новыми участниками. Через несколько лет семинар распался (1954 г.), и наши взаимоотношения свелись к дружеским встречам.

Я поступил в университет после окончания Тульского суворовского военного училища. Суворовские училища были организованы во время войны в 1943 году с намерением возродить старые традиции российского кадетского корпуса. Предполагалось, что кадет, будущий кадровьй офицер, должен получить хорошее общее образование и соответствующее воспитание. Наряду с обычной школьной программой в училище были дополнительные предметы - история дипломатии, бальные танцы и высшая математика.

В нашем взводе, или, как обычно говорят, в нашем классе, учителем математики был наш общий любимец лейтенант Георгий Иванович Бобылев. На его уроках было весело и интересно. Однажды мы не смогли продифференцировать какое-то накрученное выражение. Он, обозвав нас ремесленниками, взялся снова объяснять нам правила дифференцирования. Когда он писал на доске и класс затих, наш взводный шутник Гена Емельянов артистическим шепотом сообщил классу: "А у Энгельса написано, что научить дифференцировать можно и мартышку". "А я, Геннадий, умею еще и интегрировать," - ответил учитель, приняв тем самшім шутку. В конце четверти, вьводя итоговые оценки, он припомнил Гене эту мартышку. Дойдя до его фамилии, вслух зачитал: "Емельянов - четыре, четыре, четыре". Затем, лукаво улыбаясь, пересчитал отметки: "Раз, два, три - значит Емельянову за четверть получается тройка". Разумеется, была поставлена четверка.

В первый же год занятий в университете мне посчастливилось познакомиться с Львом Семеновичем Понтрягиным. Я знал о нем до поступления в университет из рассказов Георгия Ивановича. Он учился в университете в то же время, что и Понтрягин, и был знаком с ним. Однажды я спросил Льва Семеновича, как нужно учиться математике. Он сказал, что это очень просто - нужно заниматься ею, математикой, непрерывно, а выбор тематики в начальный период - это не очень важно. Это укрепило мою уверенность в том, что семинар Кронрода - это то, что нужно. Такая уверенность была нужна. Семинар оставлял мало времени на другие предметы, и был риск завалить экзаменационную сессию. На старших курсах, прослушав спецкурс Понтрягина по непрерьвным группам, я увлекся топологией и один год активно работал в семинаре Павла Сергеевича Александрова. В аспирантские годы моим научным руководителем был Андрей Николаевич Колмогоров.

На четвертом курсе я был назначен консултантом в одну из групп первого курса. Недели через две отстающие почему-то перестали ходить на консультации. Взамен пришли активные студенты. Так сам собою сложился мой первый кружок. Впоследствии я вместе с учениками объявлял семинары для первокурсников через каждые 2-3 года. Среди студентов, прошедших через эти семинары, были Валя Архарова, Слава Ерохин и Витя Пан, Дима Арнольд и Саша Кириллов, Марик Мельников и Гена Хенкин, Бума Фридман и Шура Туманов, Валера Белошапка и Сережа Бычков, Сережа Ивашкович и Шура Лобода, Петя Парамонов и Коля Щербина, Коля Кружилин и Степа Оревков, Володя Ежов и Саня Исаев, Миша Мищенко и Миша Смирнов, Андрей Домрин и Стефран Немировский ... Многие из них, каждый в свое время, переходили в обший болшшой семинар. Перестройка разбросала добрую половину этого семинара по разным странам, но, тем не менее, семинар продолжает работать и периодически пополняется молодежью.

Повзрослевшие участники семинара часто бывают с докладами во многих зарубежных математических центрах. С другой стороны, многие участники семинара, проживающие теперь за границей, иногда приезжают в Москву, приходят в семинар и в свою очередь приглашают друзей к себе.

2. Оценки сложности алгоритмов. Основные работы Кронрода связаны с теплотехникой и вычислительной математикой. Эти работы были отмечены Сталинской премией. Его вклад в фундаментальную математику - это введенное им понятие вариаций множеств. Разработке этого понятия посвящены две монографии - моя дипломная работа "О многомерных вариациях" (1955 г.) и книга Леонида Дмитриевича Иванова "Вариации множеств и функций" (1975 г.). 
Подмножеству $n$-мерного пространства сопоставляются вариации порядков от 0 до $n . k$-я вариация - это интеграл по пространству всех плоскостей размерности $n-k$ от числа компонент пересечения плоскости с данным множеством.

Вариации хороши тем, что они характеризуют "протяженность" множества одновременно во всех размерностях. Это обстоятельство может быть использовано при оценке сложности тех или иных математических объектов. В частности, это свойство вариаций удалось использовать для описания функциональных компактов. И в этой связи появились такие ставшие теперь привычными выражения, как "оценка сложности задачи", "оценка сложности алгоритма" и т. п.

Так, было доказано, что если в качестве меры сложности функции принять отношение числа ее аргументов к порядку ее гладкости, то получится, что почти всякая функция заданной сложности не может быть представлена суперпозичией функиий меньшей сложнос$m u$. В частности, при любых натуральных $n$ и $s$ существует $s$ раз дифференцируемая функция от $n$ переменных, не представимая суперпозицией функций той же гладкости от меньшего числа переменных (1953 г.).

Суперпозиции функций были темой моего доклада на Международном конгрессе математиков в Москве (1966 г.). В 1977 году я прочитал цикл лекций по этой тематике в калифорнийском университете в Лос-Анджелесе, куда был приглашен в качестве лектора Международного математического союза (лектор назначается Комитетом Международного математического союза по заявке какого-либо из ведущих университетов, лекции публикуются отдельным изданием).

В студенческие годы первая работа по суперпозициям функций дала мне повод познакомиться с Колмогоровым. Я попросил его представить пару моих заметок по этой работе в ДАН. Выслушав формулировку результата, он, произнеся обычное свое длинное “э ...", добавил: "Да-да, это верно, и я понимаю, как это можно сделать". Я был несколько обескуражен. Присутствовавший при разговоре Павел Сергеевич

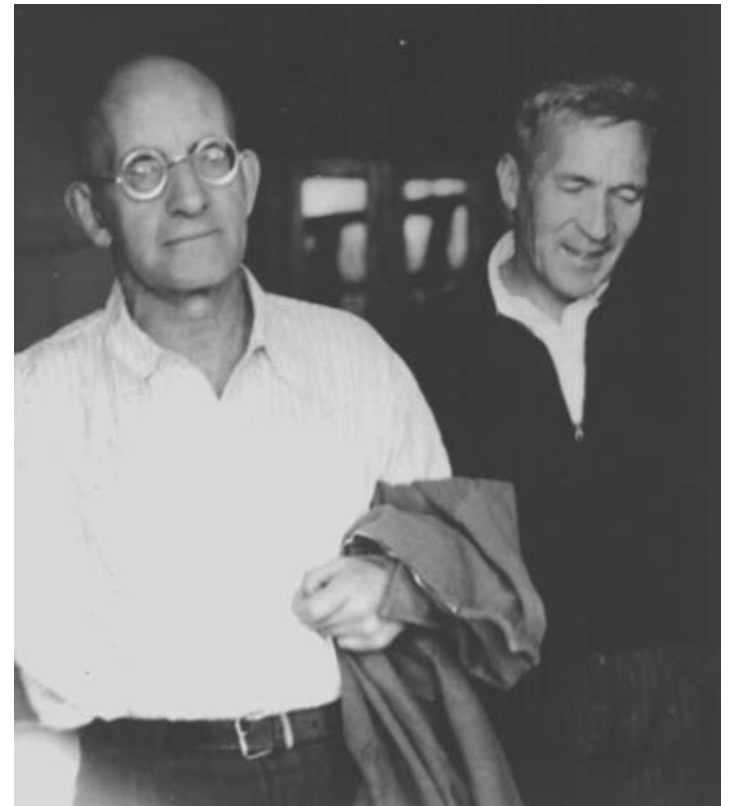

П. С. Александров и А. Н. Колмогоров Александров успокоил меня: “Толя, не обижайтесь. Андрей Николаевич понимает все". Через неделю после этого разговора, когда я пришел к Колмогорову за ответом, меня ожидал сюрприз другого рода. Он полностью переписал обе заметки и напечатал их на машинке, объяснив таким своеобразным способом, как следует излагать материал и оформлять работу для публикации.

По окончании университета я по совету Андрея Николаевича решил поступать в аспирантуру Математического института с тем, чтобы в перспективе получить там научную ставку. По его рекомендации директор института Иван Матвеевич Виноградов пригласил меня на собеседование. Все шло гладко до тех пор, пока не выяснилось, что я ученик Кронрода. Разговор обострился. Присутствовавший при этом Сергей Михайлович Никольский пытался поддержать меня. Но Иван Матвеевич, сославшись на зубную боль, прервал аудиенцию. Когда я вышел из кабинета, он сказал Никольскому: "Ничего. Никуда он от нас не денется". Как говаривал помещик Ласуков из "Осенней скуки" Н.А. Некрасова, на его и вьшло. Через 11 лет я все же получил ставку в институте, а тогда стал аспирантом Колмогорова в университете. В националшном вопросе позиция Виноградова, как видно из приведенного примера, оставляла желать лучшего. Но в остальном он был директор правильньй и уважаемьй, особо - за твердость характера и пря- 
моту. Когда группу маститых академиков попросили подписать открытое письмо, осуждавшее диссидентскую деятельность Сахарова, отказались сделать это толшко двое - Капица и Виноградов.

Для основных классов гладких и аналитических функций тем же методом, как и в случае суперпозиций, были получены оценки сложности алгоритмов вычисления функций этих классов (1957 г.). А именно, при некоторых ограничениях на компакт функций $F$ доказано следующее: если алгоритм дает аппроксимацию произвольной функции из $F$ с точностью $\varepsilon$ и при этом число параметров, определяющих функцию, равно $p$ и они входят в формулу для вычисления функции в степени (по совокупности всех параметров) не вьше, чем $k$, то вьполняется неравенство $p \log _{2}(k+1) \geqslant c H_{\varepsilon}$. Здесь $c$ - константа, определяемая компактом $F$, а $H_{\varepsilon}-\varepsilon$-энтропия компакта $F$, т.е. двоичный логариффм от числа элементов минимальной $\varepsilon$-сети компакта $F$. Известные схемы аппроксимации гладких и аналитических функций с точки зрения такого рода оценок сложности алгоритмов близки к оптимальным. Это можно понимать так, что значительно лучших схем аппроксимаций функций этих классов не существует.

Этот результат был получен, когда я был в ас-

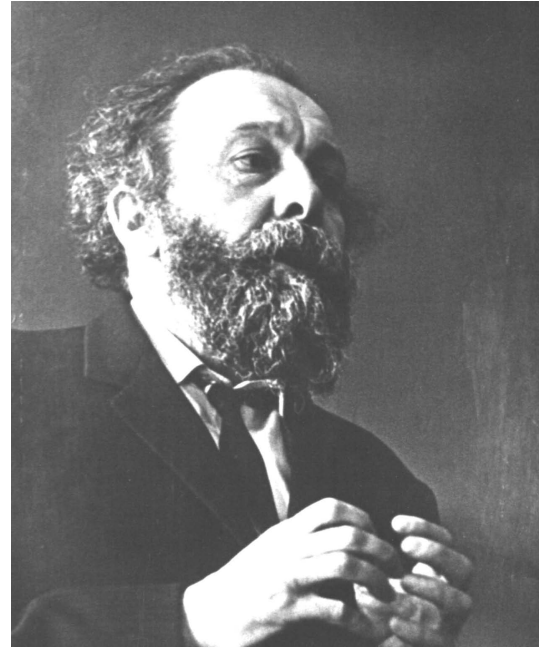

А. А. Ляпунов на лекции о кибернетике пирантуре и одновременно работал в отделе кибернетики в институте, который назьвается теперь Институтом прикладной математики им. М. В. Келдьша. Я пришел в институт с инженерной группой (М. Л. Цетлин, В. Р. Телеснин и др.). Мы занимались конструированием читающего устройства. Когда в этой работе образовывалась пауза, я занимался математикой. Отделом кибернетики в институте Келдыша руководил Алексей Андреевич Ляпунов добрьй и уступчивьй в общении, увлекающийся и одержимый в делах научных.

В то время (50-е гг.) кибернетику, так же, как генетику и многое другое, в наших учебниках называли не иначе, как буржуазной лженаукой. Ляпунов положил немало сил, чтобы организовать этот отдел и издание журнала "Основы кибернетики".

Мстислав Всеволодович Келдыш был председателем Специальной комиссии Президиума АН СССР по искусственным спутникам Земли и вместе с Сергеем Павловичем Королёвым руководил космической программой. Институт Келдыша обеспечивал математическую часть программы. В институте велась работа и по многим другим темам прикладного характера. Одновременно с этим уделялось должное внимание исследованиям в области фундаментальной математики.

Институт был хорошим местом работы. К моим результатам и Ляпунов и Келдыш относились любознательно. Но было неудобство, ставшее со временем существенным, - режим секретности. Каждый сотрудник имел ту или иную форму допуска к секретной работе, даже если он и не занимался ею. Такой режим ограничивал возможность общения, и я перешел в Математический институт в отдел Мергеляна.

Интерес к суперпозициям функций объясняется их приложениями. Приведем один пример использования суперпозиций в вычислительной математике. Пусть задан алгоритм вычисления некоторой функции от $n$ переменных и требуется указать другой алгоритм, позволяющий вычислять эту функцию одновременно с ее градиентом. Такая задача возникает, например, при вычислении экстремума функции. Спрашивается, сколь сильно возрастет число выполняемых арифметических операций. Обычно отвечают, что число операций возрастет, по крайней мере, в $n$ раз. Это неверно.

Клим Владимирович Ким заметил, что имеется возможность решить эту задачу, увеличивая число операций лишь в 3-4 раза (имеется в виду асимптотика при больших $n$ ). Идея состоит в следующем. 
Всякая формула для выполнения последователшности арифметических операций - это суперпозиция функций, каждая из которых зависит только от двух переменных. Поэтому формула для вычисления частной производной исходной функции будет суперпозицией частных производных от представляющих функций. Вычисление функции и выгисление ее производной имеют приблизительно одинаковую сложность. Поэтому для вычисления функции вместе с ее градиентом потребуется увеличения числа операций не в $n$ раз, а существенно меньше. Эту идею Ким реализовал компьютерной программой (1984 г.), и это - лучший результат по суперпозициям функций.

Еще один аналогичный вопрос с неожиданным ответом. Сколько арифметических операций требуется для того, чтобы вычислить значение многочлена степени $n$ от одной переменной? Классическая схема Горнера использет $n$ сложений и $n$ умножений. Виктор

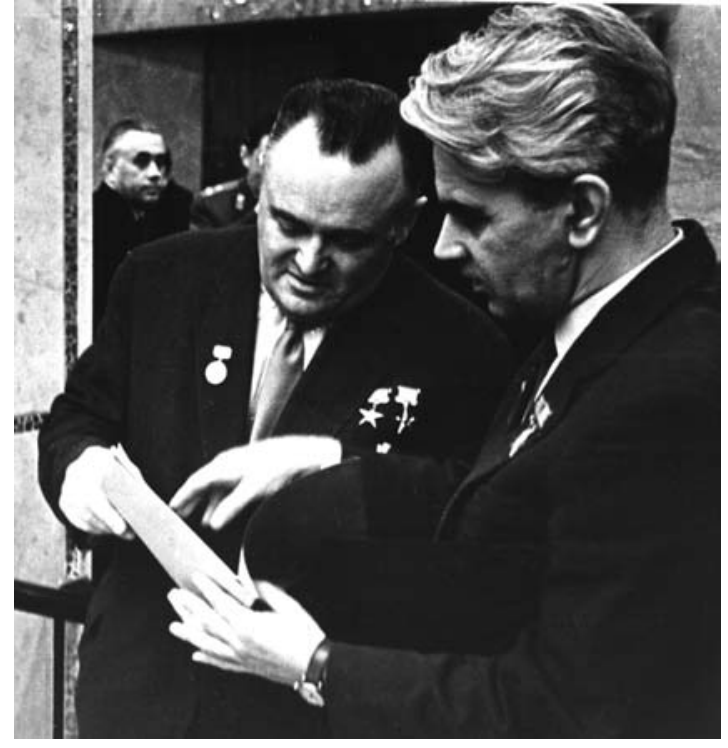

С. П. Королёв и М. В. Келдыш обсуждают космическую программу (1961г.)

Пан нашел более экономную схему, которая содержит $n$ сложений и только $\left[\frac{n}{2}\right]+1$ умножений, и доказал, что не существует схемы, которая содержит хотя бы на одну операцию меньше (1960 г.).

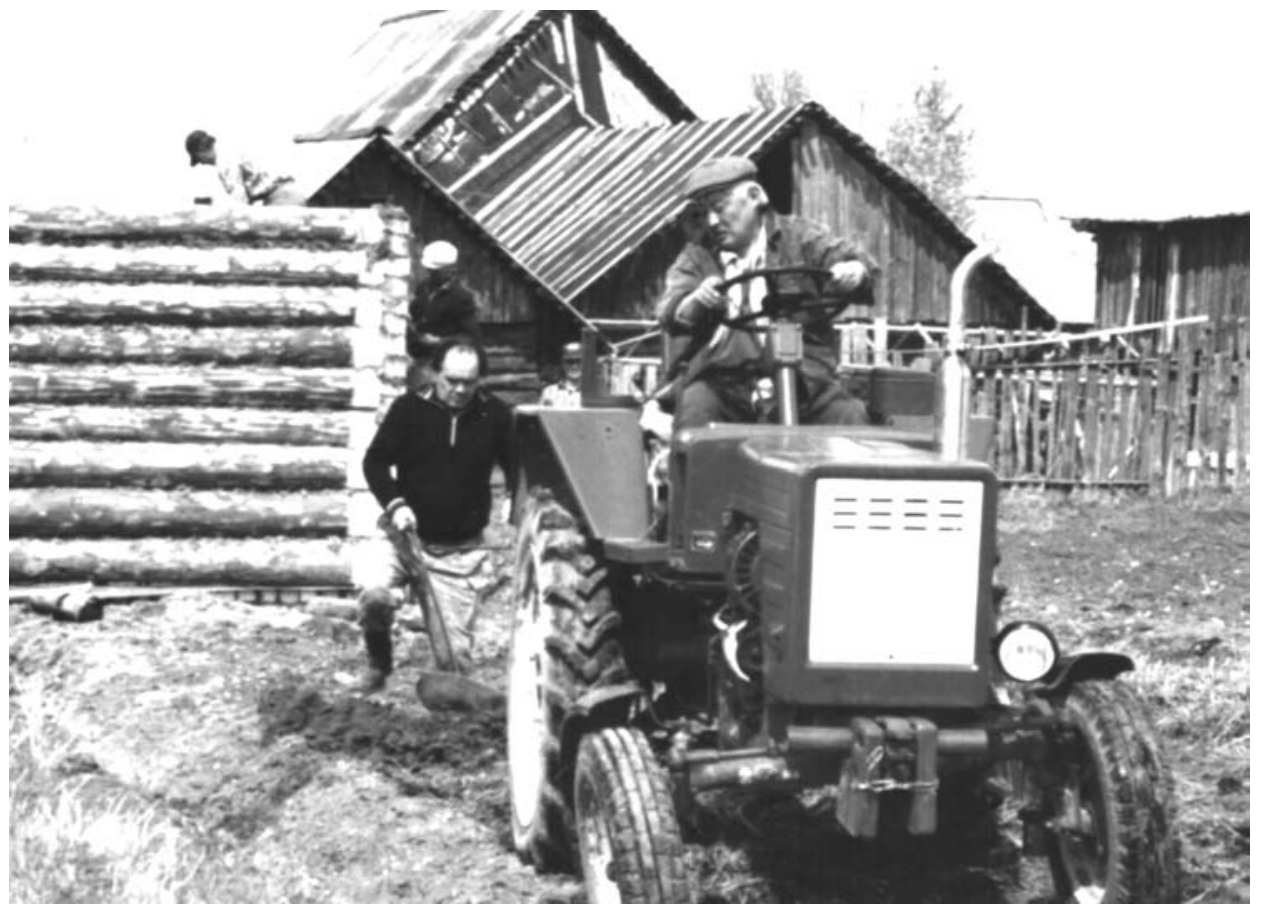

К. В. Ким и В. В. Воеводин осваивают земледелие (90-е гг.) 
3. Цифровая система записи звука. В 1933 году намечали созвать Всесоюзный съезд по вопросам реконструкции связи и развития слаботочной промьшленности. Владимир Александрович Котельников подготовил доклад “О пропускной способности 'эфира' и проволоки в электросвязи". Съезд не состоялся, но труды были опубликованы.

Основной тезис доклада Котельникова состоял в том, что количество информации, получаемой по каналу связи, пропориионально ширине полосы пропускаемых частот. Более строгая формулировка этого утверждения назьвается теперь в учебниках теоремой Котельникова: целая функция типа $\sigma$, суммируемая с квадратом на вещественной оси, представима в виде

$$
f(t)=\sum_{k=-\infty}^{\infty} f\left(t_{k}\right) q_{k}(t),
$$

где $t_{k}=\frac{k \pi}{\sigma}$ и $q_{k}(t)=\frac{\sin \left(\sigma\left(t-t_{k}\right)\right)}{\sigma\left(t-t_{k}\right)}$. Действительно, из формулы видно, что "количество информации", т.е. количество независимых чисел, которое дает сигнал со спектром $\sigma$ за единицу времени, равно $\frac{\sigma}{\pi}$.

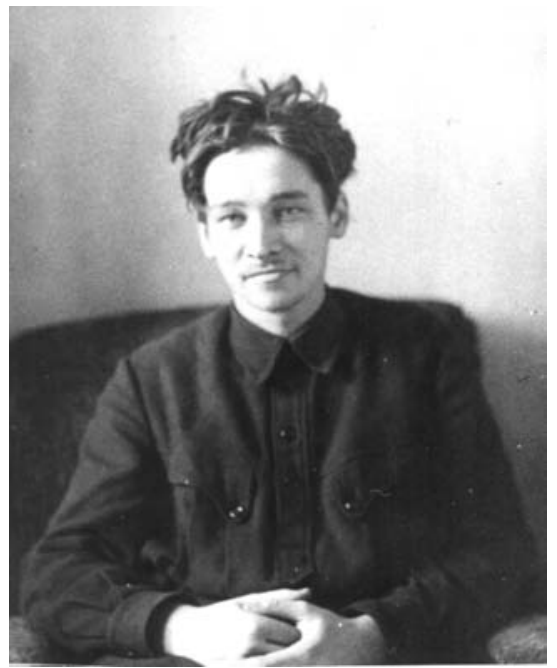

В. А. Котельников

Такие формулы были известны до Котельникова. Его находка - удачньй выбор класса функций и понимание возможности приложений. Впервые содержательно обсуждался информационньй аспект проблем связи. Его идея стала основой современной теории информации. Резултаты Котельникова отмечены многими наградами, среди которых медаль Ломоносова (АН СССР, 1981 г.) и медаль Белла (США, 2000 г.).

Доклад Котельникова затрагивал вечную проблему радиосвязи. Если канал связи имеет узкую полосу пропускаемых частот, то принимаемьй сигнал неразборчив из-за отсутствия высоких частот. Если используется широкая полоса, то возрастает шум от разного рода помех. Кроме того, всегда была проблема экономии места в эфире. Были попытки обойти эти трудности за счет какого-либо преобразования передаваемого сигнала. Котельников сумел объяснить, что эти попытки не имеют перспективы, остановив тем самым бесполезную деятельность изобретателей информационного "вечного двигателя".

Тезис Котельникова можно уточнить, используя оценки энтропии соответствующего класса функций. А.Н. Колмогоров и В.М. Тихомиров показали (1959 г.), что $\varepsilon$-энтропия (в равномерной метрике) компакта функций, получаемых ограничением на отрезок $[-T, T]$ целых функций типа $\sigma$, вещественных и ограниченных по модулю единицей на вещественной оси, асимптотически равна (при малшх значениях $\varepsilon$ и больших значениях $T$ ) величине $\frac{2 T \sigma}{\pi} \log _{2} \frac{1}{\varepsilon}$. Получается так, что если всякая функция указанного класса, передаваемая по данному каналу связи, может быть восстановлена на выходе канала с точностью $\varepsilon$, то количество информации, т.е. число двоичных знаков, которое может быть передано по этому каналу связи за единицу времени, асимптотически равно $\frac{\sigma}{\pi} \log _{2} \frac{1}{\varepsilon}$.

Формулу Котельникова в полной мере оценили в конце 70-х, когда появилась возможность заменить аналоговую систему записи сигналов цифровой. В частности, в звукозаписи стоимость нужной для этого цифрровой аппаратуры стала приемлемой, а качество воспроизведения, получаемое с компакт-дисков, оказалось почти идеальным. Но всегда остается проблема минимизации сложности алгоритмов. Так, например, в настоящее время в Интернете поток звуковых и видеозаписей стал столь широк, что часто ради экономии объема памяти и времени испольования линии связи приходится ограничиваться скромньм качеством воспроизведения. Поэтому периодически появляются новые схемы кодирования, уменьшающие объем файлов. 
В звукозаписи качество аппаратуры определяется тремя параметрами - шириной полосы воспроизводимых частот, величиной нелинейного искажения сигнала (она измеряется в процентах от средней квадратичной нормы сигнала) и динамическим диапазоном прибора (этот параметр определяется отношением норм максимального и минимального сигналов, для которых гарантируются малше нелинейные искажения). Значения двух последних параметров можно улучшать за счет хорошей точности приближения функции. Но если при этом использовать теорему Котельникова, принимая в качестве кода функции числа $\left\{f\left(t_{k}\right)\right\}$, то длина кода будет возрастать. Получается лучше, если воспользоваться формулой Вейерштрасса, восстанавливающей функцию по ее нулям, приняв в качестве кода координаты нулей.

Оказалось, и этого не ожидали, что существует система кодирования, при которой, не увеличивая длинь кода, можно получить сколь угодно широкий динамический диапазон канала связи или прибора. Это обстоятельство дает возможность понять механизм действия имеющихся систем подавления шума, используемых как в аналоговых, так и в цифровых системах записи звука. Эта работа выполнена мною совместно с Виктором Ивановичем Буслаевым (1973 г.). Кодирование сигналов и проблемы звукозаписи были темой моего (пленарного) доклада на конгрессе в Ванкувере (1974 г.).

Для видеосигналов аналогичных оценок длины кода в зависимости от динамического диапазона канала связи получить пока не удается. Такого рода резултат дал бы оценку того, сколь близки к оптимальному методы кодирования, используемые в видеоаппаратуре.

4. О тринадцатой проблеме Гильберта. Общее алгебраическое уравнение подстановкой Чирнгаузена, которая записьвается в радикалах, приводится к более простому виду. В частности, общее уравнение 7 -й степени приводится к виду $f^{7}+x f^{3}+y f^{2}+z f+1=0$. Получается, что решение общего уравнения 7-й степени является суперпозицией арифметических операций, радикалов и функции $f$, зависящей от трех переменных $x, y$ и $z$. Далњнейшее упрощение этого уравнения посредством алгебраических подстановок, по-видимому, невозможно. В списке знаменитых проблем Гильберта (1900 г.) под номером 13 эта гипотеза формулируется так: решение общего уравнения 7-й степени не представимо суперпозицией непрерывных функций от дв ух переменных. Здесь и далее, говоря о решении алгебраического уравнения, мы будем иметь в виду какую-либо однозначную ветвь решения.

Этой проблемой увлекались многие. Результат о суперпозициях гладких функций, приведенный выше в разделе 2, появился в связи с этой проблемой. Задачи по этой теме были и в моем кружке для первокурсников (1955 г.).В этом кружке лучшими были Дима Арнольд и Саша Кириллов. Оба страстные походники, они часто водили участников семинара в турпоходы. Не давали засиживаться и мне, вьводя иногда в пешие или на байдарках походы по Подмосковью. Приходили в семинар в качестве зрителей их однокурсницы (в том числе и их будущие жены). Присутствие красивых девушек подогревало соперничество. Отчасти и по этой причине семинар получился удачным. Тогда же я увлекся инженерными делами. Это занимало все мое время и, к сожалению, после года работы семинара его пришлось закрыть. Кириллов ушел к Гельфанду, а Арнольд к Колмогорову.

Колмогоров говорил, что 13-я проблема Гильерта - это хороший материал для студентов. Со временем стало ясно, что эта задача не только для студентов, и он сам увлекся ею. В результате двухлетней совместной работы Колмогорова и Арнольда было доказано, что гипотеза Гильберта ошибочна. Решающим резултатом была работа Колмогорова о возможности представления непрерьвной функции несколшких переменных суперпозицией функций от трех переменных (1956 г.).

Колмогоров рассказьвал, что идея конструкции появилась у него, когда он, по привычке просматривать иногда старые журналы, обратил внимание на статью Кронрода, в которой среди прочего рассматривались функциональные деревья. Дерево функции - это пространство компонент ее уровней. Дерево одномерно и ациклично и потому гомеоморфно укладывается на плоскость. Значения функции естественным образом переносятся на ее дерево, и тем самым функция от многих переменных оказывается в определенном смысле функцией только от двух переменных. При построении суперпозиций потребовалось введение еще одной переменной, тем самьм образовались суперпозиции функций от трех переменных. 
Колмогоров был превосходным научным руководителем. Работая со студентами, он умел предоставить ученику возможность, как говорится, сыграть соло. Так было и в данном случае. Студент 3-го курса Дима Арнольд, усовершенствовав колмогоровскую конструкцию, доказал, что всякая непрерьвная функция трех переменных представима суперпозицией непрерывных функций двух переменных, показав тем самым ошибочность гипотезы Гильберта (1957 г.).

Колмогоров нашел новую конструкцию и доказал возможнность представления всякой непрерывной функции от нескольких переменных суперпозицией непрерывных функций от одной переменной и операции сложения (1957 г.).

Этот цикл работ Колмогорова и Арнольда был сенсацией. Но вскоре было доказано, что в их конструкциях представляющие функции не могут быть гладкими даже в том случае, когда речь идет о представлении аналитических функций (1959 г.). Поэтому, имея также в виду, что почти всякая гладкая функция не представима суперпозицией гладких функций от меньшего числа переменных, можно рассчитьвать на положительное решение проблемы, т.е. возможно, что решение уравнения 7-й степени не представимо суперпозицией функций от двух переменных, разумеется, в предположении гладкости или аналитичности этих функций. С другой стороны, не исключено, что всякая алгебраическая функция нескольких переменных является суперпозицией алгебраических функций от одной переменной и арифметических операций. Таким образом, проблема остается открытой и диапазон вопросов столь же широк, как и в начале века.

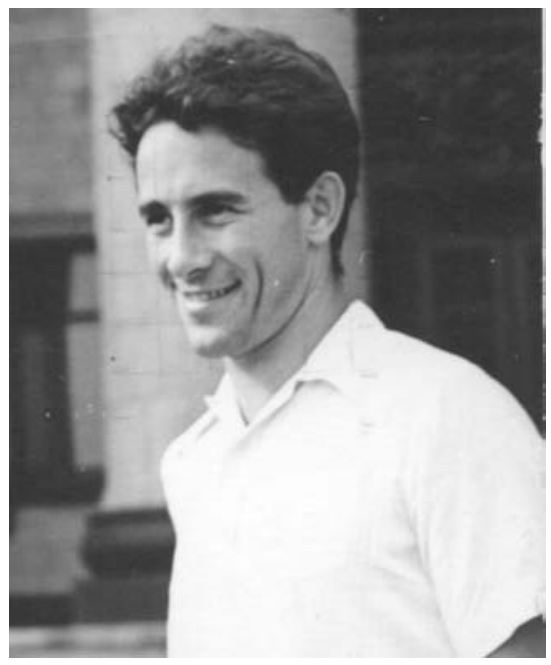

Дима Арнольд мечтает решить 13-ю проблему Гильберта

Закончив аспирантуру, Арнольдпредставил свою работу по 13-й проблеме Гильберта в качестве кандидатской диссертации. Я был на защите официальньм оппонентом. Интересно тогда высказался об Арнольде Колмогоров: "Владимир Игоревич не ест, не спит . . . нет-нет, он, разумеется, и ест, и спит, но и в это время занимается математикой”.

Израиль Моисеевич Гельфанд предложил присвоить Арнольду за решение проблемш Гильберта степень доктора наук. Такое перетягивание одеяла было несправедливо по отношению к Колмогорову. Я сказал, что опровержение гипотезы - это еще не решение проблемы по существу, тем не менее за это степень доктора можно дать, но не Арнольду, а академику Колмогорову. Дискуссия получилась шумная, но Арнольду она никак не повредила, а лишь добавила популярности. Совсем скоро после этого он получил докторскую степень за работы по динамическим системам, а мне это оппонирование припомнили и не раз.

В пятидесятые годы в программе мех-мата был курс педагогики, дополняемый практикой в школах.

В классе, где я проходил практику, многие ученики справлялись с математикой превосходно. Некоторые ребята, среди них был Дима Арнолд, охотно делали задачки из университетского курса математического анализа, которые я иногда давал им на переменах. Но мой зачетный урок сложился неудачно. Нужно было опросить четверых и дать новый материал. Первый быстро получил пятерку. Со вторым не повезло. Он не понимал простых вещей, и я по неопытности решил ему тут же все объяснить. Когда раздался звонок на перемену, он еще стоял у доски, пытаясь решить простенькое уравнение, а я, осознав свою ошибку, размышлял, нужно ли мучить этого славного юношу математикой ... Поневоле вспомнишь Мефистофеля: “Теория, мой друг, суха, но зеленеет вечно жизни древо!" (Гёте).

5. Аналитическая емкость и аппроксимации функций. Еще одна яркая звезда Сергей Никитович Мергелян. Вундеркинд и баловень судьбы, в 20 лет он доктор наук, а в $24-$ лауреат Сталинской премии и член-корреспондент Академии Наук СССР (1952 г.). Его теорема об аппроксимации функций многочленами стала классикой наравне с теоремами Вейерштрасса и 
Рунге. Пользовались успехом его лекции. Привлекало не только содержание лекций. Студенток более интересовал сам лектор - юный голубоглазый профессор.

Теорема Мергеляна дает ответ на вопрос о возможности приближения функции от одной комплексной переменной многочленом от комплексной переменной: чтобы на заданном компакте всякую непрерывную функцию, голоморфную на внутренности компакта, можно было с любой точностью равномерно приблизить многочленом, необходимо и достаточно, чтобы дополнение к компакту было связно (1952 г.).

Теорема Мергеляна завершает большой цикл работ о полиномиальных аппроксимациях (Уолш, Гартогс, Розенталь, Лаврентьев, Келдыш). В этих работах для некоторых классов компактов заданную на компакте функцию приближают функцией, голоморфной в окрестности компакта, а искомьй аппроксимирующий многочлен получается ссылкой на теорему Рунге (1885г.): всякую функцию, голоморфную в окрестности компакта со связным дополнением, можно с любой точностью равномерно приблизить на компакте многочленом.

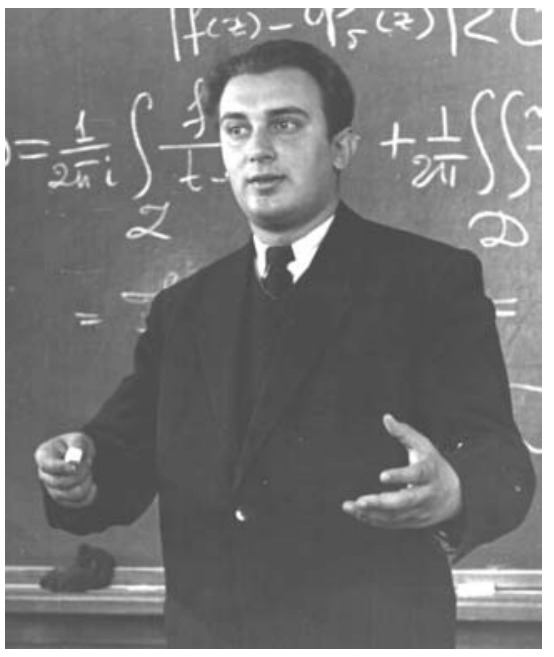

С.Н. Мергелян

В отличие от полиномиальных аппроксимаций столь же простого геометрического критерия возможности приближения функции рациональньми функциями или функциями, голоморфными в окрестности компакта (эти две задачи эквивалентны) нет, и, как будет видно из дальнейшего, быть не может. Для описания компактов, на которых такие аппроксимации возможны, потребовалось ввести характеристику множества, которую с легкой руки Славы Ерохина стали называть аналитической емкостью множества (1958 г.). По определению, аналитическая емкость множества $E$ равна $\alpha(E)=\sup \left|\lim _{z \rightarrow \infty} z f(z)\right|$. Верхняя грань берется по классу всех функций, которые непрерьвны на всей плоскости и ограничены единицей, голоморфны вне множества $E$ и равны нулю на бесконечности.

Аппроксимация функций голоморфньми функциями возможна на заданном компакте, если вблизи границы компакта в дополнении имеется место, достаточное для того, чтобы туда можно было "сдвинуть" границу компакта. Критерий возможкности аппроксимации формулируется так: для того, чтобы на компакте $E$ всякую непрерывную функцию, голоморфную на внутренности $E_{0}$ этого компакта, можно было с любой точностью равномерно приблизить функцией, голоморфной в окрестности компакта, необходимо и достаточно, чтобы для всякого открытого круга $D$ выполнялось равенство $\alpha(D \backslash E)=\alpha\left(D \backslash E_{0}\right)$ (1966 г.). Условие критерия выполняется, если, например, внутренняя граница компакта пуста, т.е. всякая его граничная точка принадлежит границе хотя бы одной из компонент дополнения. В частности, это верно, если дополнение компакта связно, и потому теорему Мергеляна можнно понимать как следствие данного критерия и теоремы Рунге.

Результат заметили. Меня пригласили докладчиком на конгресс, но на этот конгресс (Ницца, 1970 г.) меня не пустили (за подписантство).

Отметим некоторые свойства аналитической емкости. Емкость множества конечной длины равна нулю. Емкость круга равна его радиусу. При этом среди всех множеств одинаковой площади минимум значения емкости принимается только на круге. Емкость области не меньше, чем четверть ее диаметра. Весьма неожиданным и полезньм в приложениях оказалось свойство емкости, получившее название "неустойчивость емкости": если множество $E \subset \mathbb{C}$ таково, что для всякой точки $z \in \mathbb{C} \lim \sup _{r \rightarrow 0} r^{-2} \alpha(E \cap D(z, r))>0$ (здесь $D(z, r)$ - это круг радиуса $r$ с центром в точке $z)$, то $\alpha(E \cap D(z, r))=r$ для всех $z$ и $r(1958$ г.).

Значительным событием была теорема Марка Мельникова (1966 г.), дающая важную в приложениях оченку интеграла Коши: если функция $f(z)$ непрерывна на круге $|z| \leqslant 1$ и множес- 
тво $E$ точек неголоморфности функции не выходит на границу круга, то

$$
\left|\int_{|z|=1} f(z) d z\right| \leqslant c \alpha(E)
$$

где $c$ - абсолютная константа.

Эта тематика остается популярной и в настоящее время. Из нерешенных задач наиболее привлекательна с точки зрения возможных приложений гипотеза о полуаддитивности емкос$m u$ : для всякой пары компактов $A, B$ выполняется неравенство $\alpha(A \cup B) \leqslant \alpha(A)+\alpha(B)$. Этой гипотезе более сорока лет, тем не менее вопрос остается открытым даже в случае, если в правой части неравенства перед суммой в виде множителя поставить какую-либо абсолютную константу. Некоторую надежду на положительное решение этой проблемы дает работа ученика Мелникова, молодого испанского математика К. Толсы (1998 г.), в которой доказано,что свойство полуаддитивности имеет место для так назьваемой положительной аналитической емкости $\gamma^{+}$. Эта емкость определяется по обычной схеме с единственным отличием - верхняя грань берется по классу ограниченных по модулю единицей функций, представимых потенциалом Коши по положительной мере, распределенной на заданном множестве.

6. Устранимые особенности голоморфных функций. Постановка задачи описания множеств устранимых особенностей голоморфных функций и начальные результаты по этой теме принадлежат Пенлеве (1888 г.). Подмножество плоскости назьвается устранимым (для класса ограниченных голоморфных функций), если всякая ограниченная голоморфная функция, определенная в дополнении данного множества до какой-либо его окрестности, может быть голоморфно продолжена на это множество. Г. Давид доказал (1999 г.), что компакт, хаусдорфова длина которого конечна, является устранимым множеством в том и только том случае, если его линейная вариация равна нулю, иными словами, если почти на всякую прямую этот компакт проектируется в множество меры нуль. В качестве гипотезы это утверждение появилось в нашем семинаре около сорока лет назад, после того как удалось построить пример устранимого множества, длина которого не равна нулю. Заметили, что линейная вариация того экзотического множества равна нулю. Это и подсказало формулировку гипотезы. Теперь проблему Пенлеве лучше всего считать решенной, поскольку он сам имел в виду лишь множества конечной длины и никакой конкретной гипотезы у него не было.

Удачньй вариант постановки задачи об устранимых множествах предложил Евгений Прокофьевич Долженко. Он доказал (1963 г.), что компакт является устранимым множеством для класса голоморфных функций, удовлетворяющих условию Липшица с показателем $0<s<1$, в том и только том случае, если мера Хаусдорфа порядка $1+s$ этого компакта равна нулю. Ученик Джона Гарнетта молодой вьетнамский математик Нгуен Уи доказал (1977 г.), что аналогичное утверждение верно и при $s=1$. Полученные в этой работе оценки потенциала Коши имели многочисленные применения, они использовались и на подходах к решению проблемы Пенлеве.

Теорема Давида завершает большой цикл работ, некоторые из которых были представлены докладами на конгрессах (А. П. Кальдерон (1978 г.), Т. Мураи (1990 г.), П. Маттила (1998 г.)). В последние годы направление исследований по данной теме определила работа М. Мельникова о кривизне меры (1994 г.). Понятие кривизны меры приводит к постановке новых задач, и здесь можно рассчитывать на дальнейшее интересное развитие событий, в том числе и в связи с гипотезой о полуаддитивности аналитической емкости.

7. Интегральное представление функций. В 1964 году Украинская Академия Наук проводила в Ужгороде школу по комплексному анализу и топологии. Возникшие там дискуссии по проблемам многомерного комплексного анализа продолжились в нашем семинаре в Москве. Несколько первых обзорных докладов по теории функций многих комплексных переменных сделал Борис Владимирович Шабат. Он впоследствии вместе со своими учениками В. А. Зоричем, Е.М. Чиркой, С. И. Пинчуком, А. Садуллаевым и другими во многом определял выбор тематики семинара. Тогда же несколько обзорных докладов по смежным разделам комплексного анализа и математической физики сделал Василий Сергеевич Владимиров. Теперь в семинаре работу по этим разделам ведут А. Г. Сергеев и А. В. Домрин. 
Владимиров и Шабат, в прошлом фронтовики, участники Отечественной войны. Об этом можно бы и не говорить, поскольку все из их поколения воевали, но нельзя не упомянуть об одной необычной истории. В молодости Шабат в резултате несчастного случая лишился ступни. Освоив протез, он достаточно уверенно ходил и даже бегал. На фронт он уходил добровольцем, и потому медкомиссии не было. Протеза не заметили, и он попал в артиллерию. Много лет спустя после войны Борис Владимирович обратился в военкомат с просьбой выдать ему удостоверение ветерана войны. В этот раз протез заметили и удостоверение ему не дали, сказав, что в таком состоянии человек не мог быть отправлен на фронт, и тем более в артиллерию.

Несколко лет основной темой семинара были задачи по аппроксимации функций нескольких комплексных переменных. Сложность этих задач в том, что в случае многих переменных нет столь же удобного, как в случае одной переменной, интегралњного представления функции. Для полиномиальных полиэдров имеется формула А. Вейля (1931 г.), и это дает для таких полиэдров аналог теоремы Рунге. Имеются также формулы для некоторых других частных случаев областей, но общего вида записи формулы не было. Лере нашел такой общий вид, вкладьвая области в пространства большей размерности и получая ядро интегральной формулы как ограничение некоторой специальной дифференциальной формы, общей для различных областей (1956 г.). Стала понятной причина разнообразия форм записи и это помогало в ряде случаев правильно выбирать ядро в зависимости от типа области.

Значительным достижением семинара стало полученное Г. М. Хенкиньг интегральное представление функции на строго псевдовыпуклых облас$m я x$ с достаточно гладкой границей (1968 г.). Для таких областей он получил аналог теоремы Мергеляна. Хенкин был приглашенньм докладчиком на конгрессе в Варшаве (1983 г.). Его формула нашла разнообразные приложения. Тем не менее, в данной тематике вопросов больше, чем ответов. Чтобы хоть как-то охарактеризовать ситуацию, приведем две простые с виду нерешенные задачи.

Гипотеза Бишопа: объединение конечного числа замкнутых попарно непересекающихся шаров в $\mathbb{C}^{n}$ полиномиально выпукло, т.е. для всякой точки вне этого множества существует полином, равньй 1 в этой точке и по модулю меньший 1 во всех точках указанного множества.

Гипотеза Гельфанда: если дуга в $\mathbb{C}^{n}$ (гомеоморфно вложенный отрезок) полиномиально вьпукла, то всякая непрерьвная на ней функция может

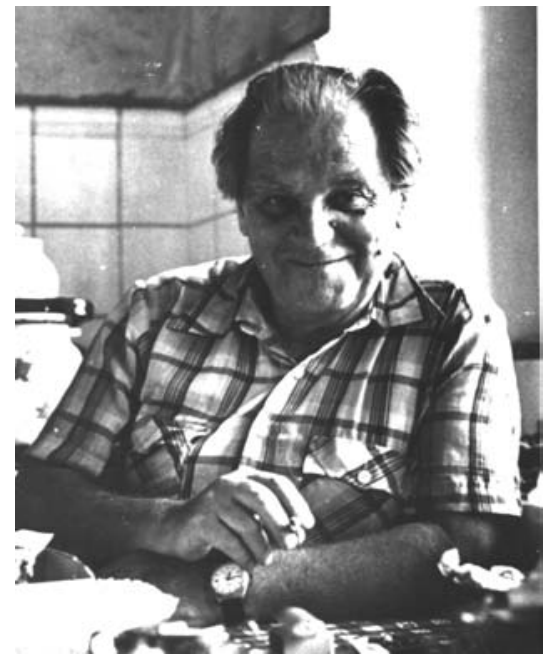

Б. В. Шабат быть с любой точностью равномерно приближена многочленом.

8. Продолжение аналитических элементов. В 1907 году Пуанкаре, занимаясь проблемой классификации областей в $\mathbb{C}^{n}$, желая свести эту проблему к классификации гиперповерхностей, в качестве примера доказал следующее: если голоморфное отображение, определенное в окрестности точки $(2 n-1)$-мерной сферы, переводит точки сферы в сферу той же размерности, то оно голоморфно продолжается на всю сферу и затем на шар и, следовательно, является дробно-линейным. Позже Александер, не зная об этой теореме Пуанкаре, вновь доказал это утверждение (1974 г.). Эту работу заметили, вспомнили о работах Пуанкаре, Э. Картана (1935 г.), Танаки (1962 г.) и других авторов по этой тематике. Появилась статья Черна и Мозера (1974 г.) об инвариантах вещественно-аналитических гиперповерхностей и так назьваемых нормальных формах гиперповерхности.

Пришла эта тематика и в наш семинар. Замечательньй резултат получил Пинчук (1978 г.): для пары компактных, строго псевдовыпуклшх, несферических, вещественно-аналитических поверхностей в $\mathbb{C}^{n}$ голоморфное отображение, заданное в окрестности какой-либо точки первой поверхности, переводящее точки первой поверхности во вторую поверхность, голоморфино продолжается по всем путям на первой поверхности (поверхность называется несферической, если 
никакая ее область не может быть биголоморфно уложена на квадрику). Доказательство использовало метрику Феффермана, приспособленную для поверхностей в $\mathbb{C}^{n}$, и потому проходило лишь для поверхностей в $\mathbb{C}^{n}$.

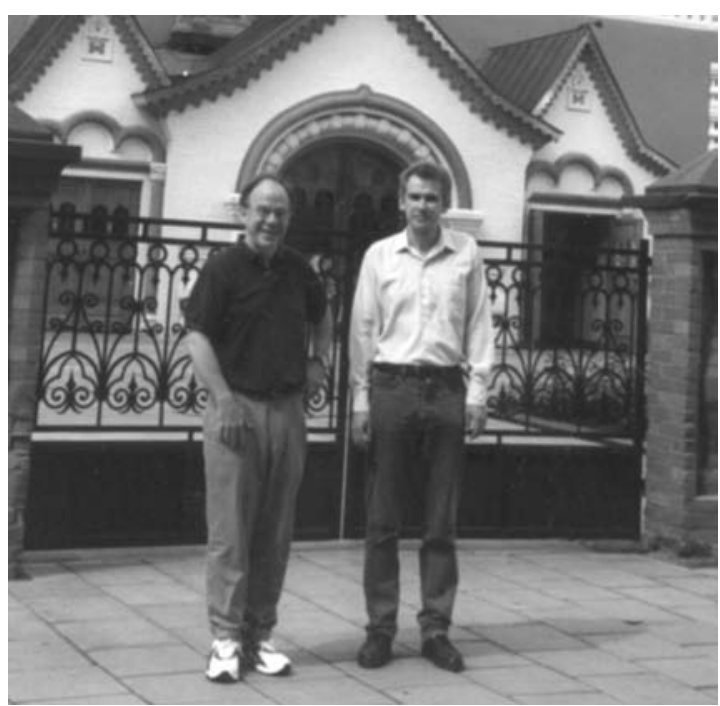

Кружилин знакомит Хаклберри с Москвой

Доказательство аналогичного утверждения для гиперповерхностей произвольных комплексных многообразий потребовало других методов. Такая теорема была доказана, и она получила название "теорема о ростке отображения" (1985 г.). Теоремаполучилась как резулттат нескольких подготовительных работ о несферических гиперповерхностях с невырожденной формой Леви.

Белошапка и Лобода показали, что для таких гиперповерхностей всякий автоморфизм, оставляющий на месте данную точку, полностью определяется ограничением линейной части отображения на комплексную касательную в этой точке (1981 г.). Для таких поверхностей с положителшно-определенной формой Леви Кружилин и Лобода доказали, что локальная группа автоморфизмов линеаризуема, т.е. при специалшном выборе системы координат все автоморфизмы одновременно оказьваются линейными (1983 г.). Для того же класса поверхностей Белошапка получил оценку радиуса сходимости степенного ряда, задающего локальный автоморфизм (1985 г.).

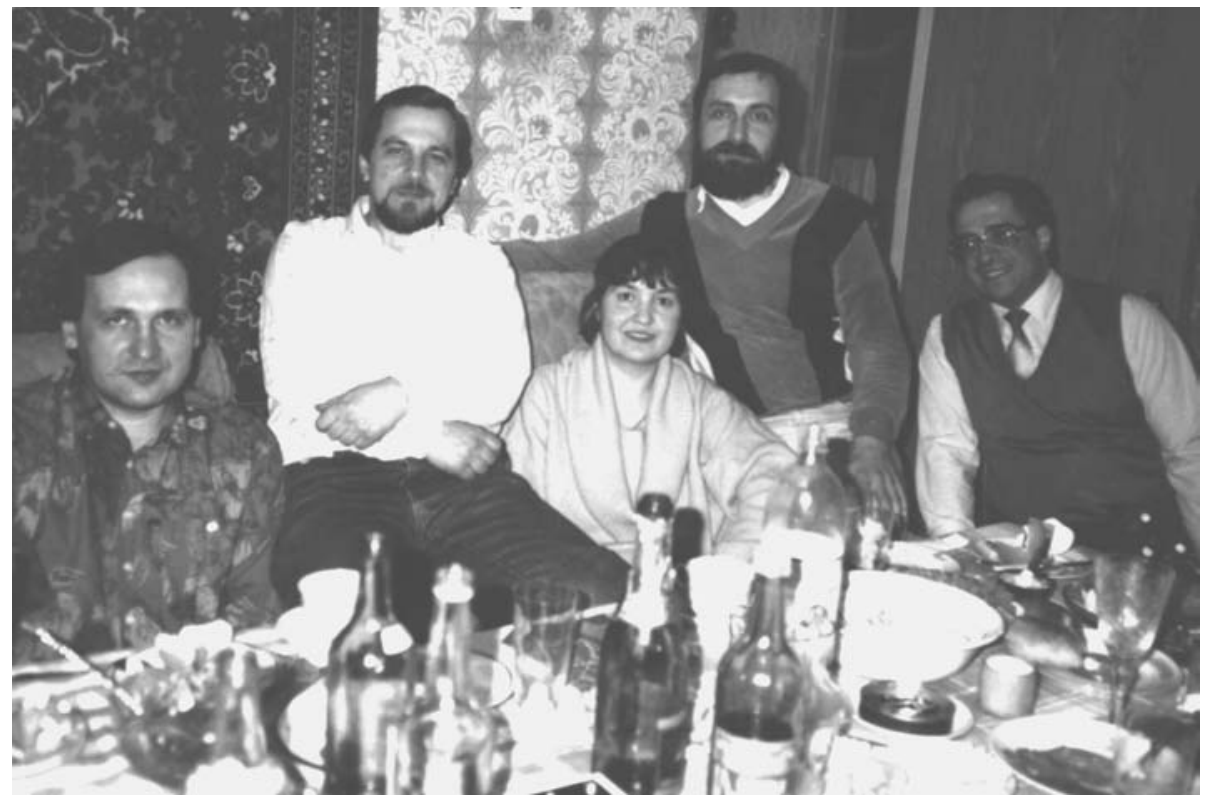

В этот день Ивашкович и Парамонов стали докторами наук (1994 г.)

(Ивашкович, Парамонов, Белошапка, Сергеев)

По этим работам было много приглашений. Были доклады в семинарах Лелона и Дольбо (институт Пуанкаре), Карлесона (институт Миттаг-Леффолера), Грауэрта (Гёттингенский уни- 
верситет), Хаклберри (Рурский университет), Манина (институт Макса Планка), разумеется, и в семинарах ряда наших университетов. Кружилин был приглашенным докладчиком по этой теме на конгрессе в Беркли (1986 г.).

Дальнейшим развитием этой тематики был цикл работ Сергея Ивашковича о продолжении голоморфных отображений комплексных пространств. В частности, им была доказана известная гипотеза Гриффитса: голоморфное отображение из области на штейновом многообразии в компактное кэлерово многообразие продолжается мероморфно на оболочку голоморфности данной области (1992 г.).

9. Гипотеза о якобиане формулируется так: если якобиан пары полиномов $P, Q$ от переменных $x, y$ равен отличной от нуля константе, то для всяких чисел $a$ и $b$ система уравнений $P(x, y)=a ; Q(x, y)=b$ имеет решение, и оно единственно. Чаще эту гипотезу формулируют иначе: если полиномиальное отображение $\mathbb{C}^{2}$ в себя локально обратимо, то оно обратимо в целом, т.е. является автоморфиимом $\mathbb{C}^{2}$. Эта проблема была поставлена в работе О. Келлеpa $(1939$ г.)

Условие полиномиальности отображения существенно. Например отображение $x^{\prime}=e^{x}$, $y^{\prime}=y e^{-x}$ необратимо, хотя якобиан равен единице. Есть более деликатньй пример (Фату, 1922 г.) - голоморфное строгое вложение $\mathbb{C}^{2}$ в себя, якобиан которого равен единице. Это тоже не автоморфизм, поскольку образ накрьвает не все пространство.

Теорема Юнга (1942 г.): полиномиальный автоморфизм пространства $\mathbb{C}^{2}$ является композицией линейных и треугольных преобразований, т.е. преобразований вида $x^{\prime}=x+c y^{n}, y^{\prime}=y$ $(c \in \mathbb{C}, n \in \mathbb{N})$. Отметим, что имеются простые примеры полиномиальных автоморфизмов $\mathbb{C}^{3}$, для которых вопрос о представимости композицией линейных и треугольных преобразований остается открытым.

Для отображений $\mathbb{R}^{2}$ в себя вопрос об обратимости допускает иную формулировку. Откажитесь от постоянства якобиана, требуя лишь локальную обратимость. Ответ получается отрицателњньй Пинчук построил (1994 г.) пример полиномиального отображения $\mathbb{R}^{2}$ в себя, которое локалњно обратимо, но в целом необратимо (Пинчук был приглашенным докладчиком на конгрессе в Берлине (1998 г.)). Тем не менее, рассчитьвать на контрпример для классического варианта гипотезы особенно не приходится. $\mathrm{K}$ тому же известно, что для полиномиальных отображений $\mathbb{C}^{2}$ в себя степени не выше ста гипотеза верна (Мо, 1983 г.).

Пусть $f$ - полиномиальный эндоморфизм $\mathbb{C}^{2}$. Для понимания геометрии такого отображения полезна следующая процедура. $\mathbb{C}^{2}$ пополняется до $\mathbb{C P}^{2}$ с последующим выполнением раздутий точек неопределенности данного отображения. В резултате получается компактное комплексное многообразие, состоящее из $\mathbb{C}^{2}$ и дерева сфер, и голоморфное ото-

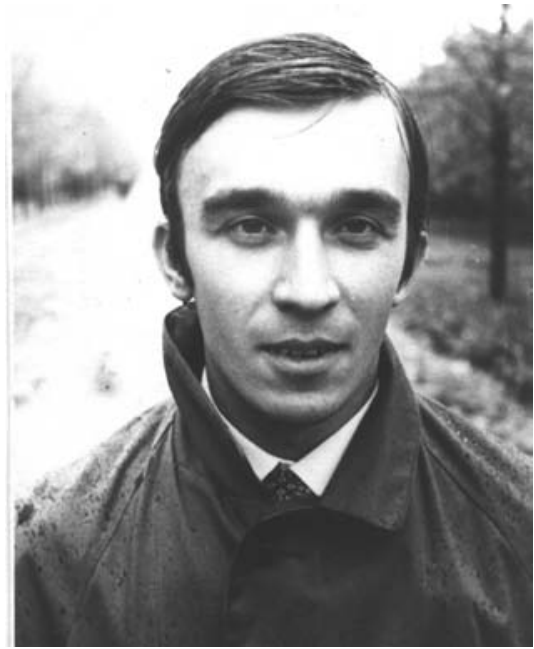

Сережа Пинчук тоже мечтает решить проблему якобиана

бражение этого многообразия в $\mathbb{C P}^{1} \times \mathbb{C P}^{1}$, совпадающее на $\mathbb{C}^{2}$ с $f$. Структура дерева вклеенных сфер такова, что, удалив из многообразия некоторые из этих сфер, можно получить новое многообразие $M$, состоящее из $\mathbb{C}^{2}$ и конечного числа попарно непересекающихся комплексных прямых $\left\{L_{j}\right\}$ и такое, что на всякой из этих прямых каждая (из двух) отображающая функция или тождественно равна бесконечности, или вовсе не принимает значение бесконечность. Предполагается, что мы удаляем минимальное число сфер и в этом смысле получаем полньй набор пополняющих прямых.

Если гипотеза о якобиане не верна, то найдется локально обратимый полиномиальный эндоморфизм $f$ пространства $\mathbb{C}^{2}$, которьй не обратим в целом. Удалим из соответствующего многообразия $M$ те прямые из набора $\left\{L_{j}\right\}$, на которых хотя бы одна из отображающих функций равна 
бесконечности. Получится новое многообразие $M^{*}$, состоящее из $\mathbb{C}^{2}$ и нескольких комплексных прямшхх. Отображкение $f$ голоморфно переводит $M^{*}$ в $\mathbb{C}^{2}$. Оно собственно, локально обратимо вне оставленных прямых и, в силу необратимости, имеет ветвление хотя бы вдоль одной из этих прямых. Получилась весьма экзотическая разветвленная накрывающая $\left(M^{*}, f\right)$ над $\mathbb{C}^{2}$ и требуется доказать, что такой накрьвающей быть не может.

Оказалось, что если не требовать голоморфной структуры поверхности, то такую накрывающую поверхность построить можно (1970 г.), а именно, существует трехлистная накрьвающая над $\mathbb{C}^{2}$, склеенная из $\mathbb{R}^{4}$ и $\mathbb{R}^{2}$ и такая, что на $\mathbb{R}^{4}$ проекция локально обратима, а вблизи $\mathbb{R}^{2}$ проекция двулистна. Контрпримера к гипотезе о якобиане из этого не получилось. Степа Оревков показал, что такой же накрывающей поверхности с голоморфиной структурой не существует (1986 г.). Тем не менее, этот пример работает и в настоящее время в тех случаях, когда приходится искать ошибку в очередном доказательстве гипотезы. На протяжении 15 лет (1955-1970 гг.) гипотеза считалась доказанной, и опровергающие аргументы удалось найти лишь одновременно с построением этого примера.

Группа одномерных гомологий с компактным носителем упомянутого выше многообразия $M$, получаемого при разрешении особенностей полиномиального отображения, тривиальна, а группа вторых гомологий - не тривиальна. Каждая из указанных комплексных прямых $\left\{L_{j}\right\}$ порождает нетривиальный цикл. Таким циклом является, например, гладко погруженная в $M$ сфера, имеющая с данной прямой индекс пересечения 1 . Такую сферу можно получить, склеивая вдоль границы два диска - мальй диск, трансверсально пересекающий выбранную прямую, и диск, лежащий в $\mathbb{C}^{2} \subset M$. В семинаре мы привьщли называть такую поверхность пробной сферой. Название оправдывается тем, что топологические характеристики этих сфер определяют во многом свойства многообразия $M$. В частности, эти характеристики позволяют иногда судить об обратимости соответствующего отображения.

Большим успехом семинара были работы Стеффана Немировского (1998 г.). Используя новые для обсуждаемой тематики методы - теорию инвариантов Зайберга-Виттена, он дал ответ на некоторые возникшие в семинаре в 80-е годы вопросы об оболочках голоморфиности пробных сфер. В частности, им доказано, что еслигладко вложенная в $\mathbb{C} P^{2}$ вещественно-двумерная поверхность имеет с бесконечностью ненулевой индекс пересечения и в окрестности этой поверхности есть непостоянные голоморфные функции, то род поверхности не меньше, чем 3 , и эта оценка точна. Получается, что на гомологически нетривиальной гладко вложенной в $\mathbb{C P}^{2}$ сффере (в частности, и на пробной сфере) нет непостоянных голоморфиных функций.

Он доказал также, что к области в $\mathbb{C}^{2}$, биголоморфно эквивалентной шару, нельзя подклеить аналитический диск так, чтобы граница диска лежала на границе области, а вся его внутренность была бы вне области. Если верно аналогичное утверждение для биголоморфного образа шара, лежащего не в $\mathbb{C}^{2}$, а на алгебраической накрывающей над $\mathbb{C}^{2}$, то это даст доказателство гипотезы о якобиане. За эти работы Немировский награжден премией Европейского математического общества для молодых математиков (Барселона, 2000 г.).

Разрешение особенностей полиномиального автоморфизма $\mathbb{C}^{2}$ реализуется композицией так называемых треугольных цепочек раздутий. В частности, треуголному преобразованию $\mathbb{C}^{2}$ соответствует всего лишь одна треугольная цепочка сфер $\gamma_{0}, \gamma, \gamma_{1}, \gamma_{2}, \ldots, \gamma_{2 n}$, которая получается следующим образом. Сфера $\gamma$ получается раздутием какой-нибудь точки сферы $\gamma_{0}$, пополняющей $\mathbb{C}^{2}$ до $\mathbb{C P}^{2}$. При $k=1, \ldots, n$ сфера $\gamma_{k}$ получается раздутием точки $p_{k}=\gamma \cap \gamma_{k-1}$. При $k=n+1, \ldots, 2 n$ сфера $\gamma_{k}$ получается раздутием точки, принадлежащей лишь последней из ранее полученных сфер, т.е. сфере $\gamma_{k-1}$. Характеризующим свойством треуголњной цепочки является то, что, стянув в точку все сферы $\gamma_{0}, \ldots, \gamma_{2 n-1}$, мы вновь получим $\mathbb{C P}^{2}=\mathbb{C}^{2} \cup \gamma_{2 n}$.

Пусть $M$ - многообразие, состоящее из $\mathbb{C}^{2}$ и комплексной прямой, полученное из $\mathbb{C P}^{2}$ выполнением цепочки раздутий с последующим удалением всех сфер (включая бесконечно удаленную сферу из $\mathbb{C P}^{2}$ ), кроме последней. Пусть, далее, $S$ - пробная сфера этого многообразия. Возникает вопрос, как связаны топологические свойства пробной сферы и структура дерева сфер, возникших при выполнении данной цепочки раздутий. Естественно считать, что дерево минимально, т.е. никакое из раздутий не могло быть опущено при построении многообразия. При рассмотрении конкретных примеров полезен следующий критерий треугольности (1999 г.): 
цепочка раздутий, реализующая многообразие $M$, является композицией треугольных цепочек в том и толшко том случае, если для пробной сферы $S$ индекс самопересечения $S^{2}=1$ и значение канонического класса $K_{M} \cdot S=-3$. Треугольная цепочка определяет автоморфизм, и потому при обсуждении обратимости отображения такую цепочку можно стянуть в точку (всю, кроме последней сферы) и тем самым не обращать на нее внимания.

Пусть пробная сфера многообразия $M$ имеет параметры $S^{2}=-3$ и $K_{M} \cdot S=1$. Именно такие параметры имеет пробная сфера приведенной выше экзотической поверхности. Из критерия треугольности, хотя и не просто, но следует, что цепочка раздутий, порождающая многообразие $M$, состоит из композиции треугольных цепочек и одной простой цепочки из четьрех раздутий. Здесь, называя цепочку простой, мы имеем в виду, что на каждом шагу раздувается точка, принадлежащая лишь последней из ранее полученных сфер. Этот пример интересен тем, что подсказывает простейший частный случай гипотезы о якобиане, которьй пока еще не поддается решению.

"Упражнение": Верно ли, что если пара многочленов $P, Q$ такова, что функции $P\left(x y^{3}+y^{2}, 1 / y\right)$ и $Q\left(x y^{3}+y^{2}, 1 / y\right)$ также являются многочленами от $x, y$, то якобиан исходной пары $P, Q$ где-нибудь в $\mathbb{C}^{2}$ обращается в 0 . Использованная здесь замена переменных получается переходом к одной из координатных карт, накрывающих бесконечность, с последующим выполнением простой цепочки из четырех раздутий. Отметим, что в случае, когда число раздутий меньше, чем 4 , аналогичное утверждение верно.

10. О миграции. Гипотеза о якобиане была темой моего доклада на конференции "Manifolds-73" в Токио (1973 г.). Это была большая и представительная конференция, и там состоялось несколько полезных для меня встреч. Я познакомился с Ш. Кобаяши и Х. Хиронакой. Контакты с ними тремя годами позже продолжились в США (Беркли и Гарвард). Поездка на конференцию в Токио запомнилась особо, поскольку это была моя первая поездка за границу. Впоследствии я побьвал во многих странах, посетив с лекциями с полсотни университетов.

А в то время поездки за границу случались, как известно, редко. Причины этого общеизвестны. Приведу один типичньй для того времени пример. Наш коллега, математик, Есенин-Вольпин за излишне эмоциональную реакцию на события тех дней попалв психушку. Математики, собрав более ста подписей, направили властям письмо с требованием освободить его. Его освободили, и он через несколько лет эмигрировал в США, а все подписавшие это письмо стали невыездными.

Впоследствии участники этих событий по разному распорядились своими судьбами. Подписанты гордятся тем, что приблизили наступившее светлое будущее, и при этом многие из них уезжают из страны.

А Татьяна Великанова, отсидев срок с последующей ссылкой за активное участие в диссидентском движении, занимается теперь любимым делом - учит математике москов-

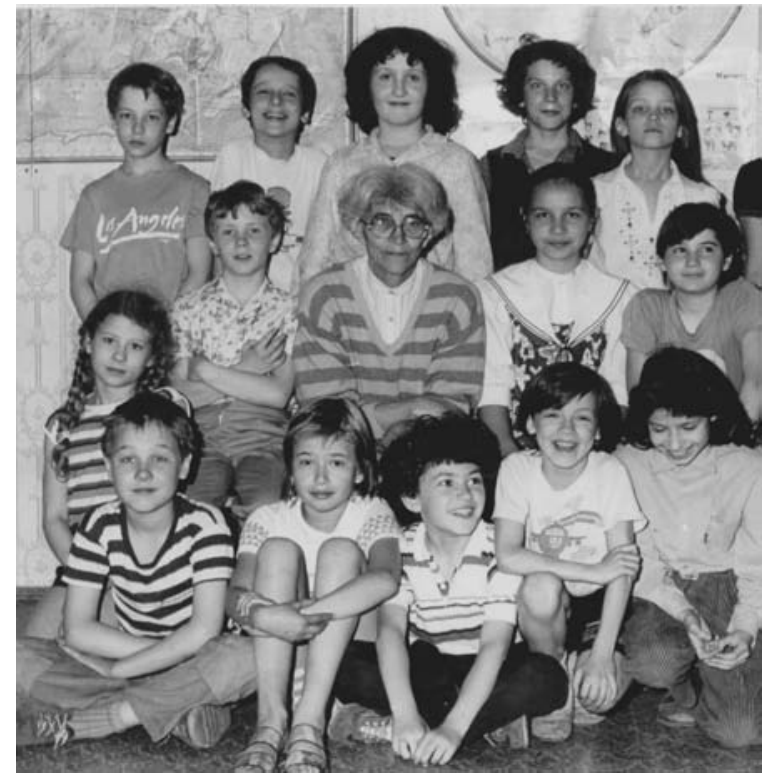

Татьяна Михайловна Великанова и будущие математики

ских ребят и получает от этого, как она сама говорит, большое удовольствие. По окончании университета она отказалась от аспирантуры, сказав, что хочет работать в школе (1954 г.), но ее мечта осуществилась лишь в конце восьмидесятых. 
Наряду с ограничениями на поездки за границу были и другие сложности общения, в том числе языковый барьер. Отдохнем немного - упомяну о встрече Шеннона с Колмогоровым в Москве. Колмогоров владел немецким и французским язьками. Свободно читал на английском, но его разговорный английский был не вполне хорош. В разговоре с Колмогоровым Шеннон с ноткой сочувствия высказал сожаление, что они плохо понимают друг друга. Колмогоров ответил, что международных языков пять, он владеет тремя, и если бы его собеседник тоже владел тремя, то проблем бы не было.

Перестройка изменила многое - появилась возможность поехать куда угодно, зарплата бюджетников стала нищенской . . . Спрашивается, если ты умен, то почему же такой бедньй? Многие наши математики разъехались: Манин - в Бонне, Арнольд и Хенкин - в Париже, Мельников - в Барселоне, Немировский собирается в Бохум ... Некоторые уехали, по-видимому, насовсем, другие - работают полгода там, полгода здесь. Покинутые ими семинары теперь уже не те, что были раньше. До перестройки советские математики на нескольких конгрессах получали по 30-50 из 150-170 секционных докладов и по 2-4 из 15-17 пленарных докладов. А на конгрессе в Берлине (1998 г.) от России был лишь один секционный доклад и ни одного пленарного. Уехавшие россияне получили поболшше, но вдвое меньше того, что было раньше. Видно, в поисках заработка и они теряют форму. Разумеется, не все. Манин всегда будет Манин, и Арнолд тоже ...

Иногда говорят, что эмиграция поможет сохранить научные кадры страны. Обещают, что когда экономическая ситуация нормализуется, многие вернутся . . К Кто знает? Быть может они и правда верят в это ...

Проницательньй читатель, конечно же, понял, что нашей целью было обсуждение трех интересных проблем XXI века, о решении которых сейчас приходится лишь мечтать ... 